\title{
BMJ Open Evaluation of the associations between changes in intraocular pressure and metabolic syndrome parameters: a retrospective cohort study in Japan
}

Hiroshi Yokomichi, ${ }^{1}$ Kenji Kashiwagi, ${ }^{2}$ Kazuyoshi Kitamura, ${ }^{2}$ Yoshioki Yoda, ${ }^{3}$ Masahiro Tsuji, ${ }^{3}$ Mie Mochizuki, ${ }^{4}$ Miri Sato, ${ }^{5}$ Ryoji Shinohara, ${ }^{5}$ Sonoko Mizorogi, ${ }^{1}$ Kohta Suzuki, ${ }^{1}$ Zentaro Yamagata ${ }^{1}$

To cite: Yokomichi $\mathrm{H}$, Kashiwagi K, Kitamura K, et al. Evaluation of the associations between changes in intraocular pressure and metabolic syndrome parameters: a retrospective cohort study in Japan. BMJ Open 2016;6: e010360. doi:10.1136/ bmjopen-2015-010360

- Prepublication history for this paper is available online. To view these files please visit the journal online (http://dx.doi.org/10.1136/ bmjopen-2015-010360).

Received 24 October 2015 Revised 2 February 2016 Accepted 7 March 2016

CrossMark

For numbered affiliations see end of article.

Correspondence to Dr Hiroshi Yokomichi; hyokomichi@yamanashi.ac.jp

\section{ABSTRACT}

Objective: The contributions of highly correlated cardiovascular risk factors to intraocular pressure (IOP) are not clear due to underlying confounding problems. The present study aimed to determine which metabolic syndrome parameters contribute to elevating IOP and to what extent.

Design: Retrospective cohort study.

Setting: A private healthcare centre in Japan.

Participants: Individuals who visited a private healthcare centre and underwent comprehensive medical check-ups between April 1999 and March 2009 were included (20 007 in the cross-sectional study and 15747 in the longitudinal study).

Primary and secondary outcome measures:

Changes in IOP were evaluated in terms of ageing and changes in metabolic syndrome parameters. Pearson's correlation coefficients and mixed-effects models were used to examine the relationship of changes in IOP with ageing and changes in metabolic syndrome parameters in cross-sectional and longitudinal studies, respectively.

Results: In the cross-sectional study, IOP was negatively correlated with age and positively correlated with waist circumference, high-density lipoprotein cholesterol (HDL-C) levels, triglyceride levels, systolic blood pressure (SBP), diastolic blood pressure (DBP) and fasting plasma glucose (FPG) levels. In the longitudinal multivariate analysis, the associated IOP changes were $-0.12(p<0.0001)$ $\mathrm{mm} \mathrm{Hg}$ with male sex; $-0.59(p<0.0001) \mathrm{mm} \mathrm{Hg}$ with 10 years of ageing; $+0.42(p<0.0001) \mathrm{mm} \mathrm{Hg}$ with $1 \mathrm{mmol} / \mathrm{L}$ increase in $\mathrm{HDL}-\mathrm{C}$ levels; +0.092 $(p<0.0001) \mathrm{mm} \mathrm{Hg}$ with $1 \mathrm{mmol} / \mathrm{L}$ increase in triglyceride levels; $+0.090(p<0.0001) \mathrm{mm} \mathrm{Hg}$ with $10 \mathrm{~mm} \mathrm{Hg}$ increase in SBP; +0.085 ( $p<0.0001)$ $\mathrm{mm} \mathrm{Hg}$ with $10 \mathrm{~mm} \mathrm{Hg}$ increase in DBP; and+0.091 $(p<0.0001) \mathrm{mm} \mathrm{Hg}$ with $1 \mathrm{mmol} / \mathrm{L}$ increase in $\mathrm{FPG}$ levels.

Conclusions: Elevation of IOP was related to longitudinal worsening of serum triglyceride levels, blood pressure and FPG and improvement in serum HDL-C levels.

\section{Strengths and limitations of this study}

- This study included a large sample size (20 007 participants in the cross-sectional analyses and 15747 participants in the longitudinal analyses).

- The longitudinal multivariate analysis modelled lifestyle-related systemic parameters together that potentially affect intraocular pressure.

- The mixed-effects models enabled repeated measurements to quantify the change in intraocular pressure in relation to the change in lifestyle-related systemic parameters.

- Interventional research on effect of lifestyle modifications on intraocular pressure among ophthalmological patients is warranted.

- Intraocular pressure was measured by noncontact tonometry and not with a Goldmann applanation tonometer.

\section{INTRODUCTION}

The Framingham Eye Study and the Baltimore Eye Survey revealed that $4-7 \%$ of people aged $\geq 40$ years have elevated intraocular pressure (IOP). ${ }^{12}$ Since the literature indicates that in patients with glaucoma, lower IOP within the normal range (10$21 \mathrm{~mm} \mathrm{Hg}$ ) decreases the risk of visual field deterioration in comparison with higher IOP within the normal range, ${ }^{3-6}$ evidence of IOP reduction is necessary.

Previous studies suggest possible moderate associations between IOP elevation and cardiovascular risk factors. ${ }^{7} 8$ Physiology clearly explains systemic hypertension as a risk factor for IOP elevation ${ }^{9}{ }^{10}$; however, it remains unclear whether all cardiovascular risk factors are related to IOP elevation. ${ }^{11-14}$ For example, ageing, a well-known cardiovascular risk factor, may affect IOP, but the results of previous studies have not been consistent among Caucasians, Asians and 
African-Americans; ageing reportedly increases IOP among European and American populations ${ }^{15-17}$ but decreases it in Asians. ${ }^{18-20}$ Furthermore, even if several cardiovascular risk factors have deleterious effects on IOP, it is unclear to what extent the IOP elevation can be attributed to each risk factor. ${ }^{21}{ }^{22}$ Specifically, previous studies have focused on the fact that obesity and age-related factors are highly correlated and therefore result in confounding problems that make it difficult to estimate the contribution of each cardiovascular risk factor to IOP. ${ }^{23-25}$

Parameters indexed in the definition of metabolic syndrome are used to easily assess the lifestyles of healthy individuals and the related cardiovascular risks. Since the parameters are modified by changes in diet and physical activities, people are more likely to set their health goals at improving the parameters. ${ }^{26}$ Recent observational studies have suggested that lifestyle and physiological factors affect IOP in healthy individuals without glaucoma ${ }^{27} 28$ and that along with blood pressure, other metabolic syndrome parameters such as waist circumference, plasma lipid levels and plasma glucose levels may also be associated with IOP elevation. ${ }^{29} 30$ However, the analyses have not yet solved the aforementioned controversy regarding confounding problems of the correlated explanatory parameters. In addition, they have also not quantified the level of IOP increase associated with a deterioration in the metabolic syndrome parameters. This study aimed to determine which metabolic syndrome parameters elevate IOP and to what extent in a cohort of ophthalmologically healthy individuals who had undergone medical check-ups.

\section{METHODS}

\section{Study participants}

This retrospective cohort study used data collected from residents of Yamanashi Prefecture, Japan, who visited a private healthcare centre and underwent a paid comprehensive medical check-up service between April 1999 and March 2009. To exclude the effect of ocular hypotensive therapy that would largely decrease IOP and affect the investigated associations, individuals with funduscopic findings during this period were excluded from the study. Only the first visit in a single fiscal year from April to March was considered for each participant. Hence, the maximum number of participant visits was 10 in the study data, and data from the second and subsequent visits during a fiscal year were excluded. For the cross-sectional study, we analysed data that were obtained between April 2008 and March 2009. For the longitudinal study, we included data for participants who had 3-10 visits between April 1999 and March 2009.

\section{Measurements}

During the medical check-ups, we measured IOP, waist circumference, blood pressure and serum markers of metabolic syndrome. All medical measurements were recorded between 9:00 and 12:00. Serum markers were assessed from blood samples that were collected in the morning before breakfast. IOP was measured with a non-contact tonometer (NT-3000, Nidek, Tokyo), and IOP levels in the right eyes were analysed. Blood pressure was measured on the upper right arm while the participants were seated. The baseline body mass index (BMI) was calculated as weight in kilograms divided by the square of height in metres.

\section{Statistical analyses}

To assess the relationship between metabolic syndrome and IOP in the cross-sectional study, Pearson's correlation coefficients with Bonferroni correction for multiple comparisons were calculated to determine the association between IOP and waist circumference, highdensity lipoprotein cholesterol (HDL-C) levels, triglyceride levels, systolic blood pressure (SBP), diastolic blood pressure (DBP) and fasting plasma glucose (FPG) levels. To determine the association between IOP and the severity of metabolic syndrome in the cross-sectional study, the mean IOP levels were represented with respect to the numbers (0-5) of positive metabolic syndrome parameters according to the diagnostic criteria. The diagnostic criteria were based on the International Diabetes Federation guidelines. ${ }^{31}$ The five identified parameters of metabolic syndrome were a waist circumference of $\geq 85 \mathrm{~cm}$ in men and $\geq 90 \mathrm{~cm}$ in women; triglyceride levels of $\geq 1.7 \mathrm{mmol} / \mathrm{L}(150 \mathrm{mg} / \mathrm{dL})$ or specific treatment for this lipid abnormality; HDL-C levels of $<1.03 \mathrm{mmol} / \mathrm{L}(40 \mathrm{mg} / \mathrm{dL})$ in men and $<1.29 \mathrm{mmol} / \mathrm{L}$ $(50 \mathrm{mg} / \mathrm{dL})$ in women or specific treatment for this lipid abnormality; SBP of $\geq 130 \mathrm{~mm} \mathrm{Hg}, \quad$ DBP of $\geq 85 \mathrm{~mm} \mathrm{Hg}$ or treatment of previously diagnosed hypertension; and FPG levels of $>5.6 \mathrm{mmol} / \mathrm{L}(100 \mathrm{mg} / \mathrm{dL})$ or previously diagnosed type 2 diabetes. The Jonckheere-Terpstra trend test was used to assess the significance of the trend in IOP with respect to the numbers of positive metabolic syndrome parameters. ${ }^{32}$ Univariate and multivariate mixed-effects models with a random intercept for participants were used to longitudinally assess the relationship between changes in IOP and metabolic syndrome parameters. ${ }^{33}$ Since waist circumference was measured only during the past three fiscal years (2006-2008) during the observed 10-year period, it was not included in the longitudinal analyses. Before conducting the multivariate analysis, we checked the multicollinearities among all the explanatory variables, particularly between SBP and DBP, which could seriously interfere with the estimates of interest. ${ }^{34}$ In terms of variance inflation factors $\leq 4$, no multicollinearity was detected. ${ }^{35}$ The used model examples for the longitudinal analyses are represented below.

Univariate analysis with SBP: $(\text { Change in IOP })_{\mathrm{ij}}$

$$
=\mathrm{a}_{\mathrm{i}}+(\text { Change in SBP })_{\mathrm{ij}}+\varepsilon_{\mathrm{ij}}
$$


Multivariate analysis: $(\text { Change in IOP })_{\mathrm{ij}}=\mathrm{b}_{\mathrm{i}}+(\text { Ageing })_{\mathrm{ij}}$

$+(\text { Change in HDL-C levels })_{\mathrm{ij}}$

$+(\text { Change in triglyceride levels })_{\mathrm{ij}}+(\text { Change in SBP })_{\mathrm{ij}}$

$+(\text { Change in DBP })_{\mathrm{ij}}+(\text { Change in FPG levels })_{\mathrm{ij}}+\delta_{\mathrm{ij}}$

$\mathrm{i}$ for participants; $\mathrm{j}$ for time points.

$\mathrm{a}_{\mathrm{i}} \sim \mathrm{N}\left(0, \sigma_{\mathrm{a}}{ }^{2}\right), \varepsilon_{\mathrm{ij}} \sim \mathrm{N}\left(0, \sigma_{\varepsilon}{ }^{2}\right), \mathrm{a}_{\mathrm{i}}$ and $\varepsilon_{\mathrm{ij}}$ are independent of each other.

$\mathrm{b}_{\mathrm{i}} \sim \mathrm{N}\left(0, \sigma_{\mathrm{b}}{ }^{2}\right), \delta_{\mathrm{ij}} \sim \mathrm{N}\left(0, \sigma_{\delta}{ }^{2}\right), \mathrm{b}_{\mathrm{i}}$ and $\delta_{\mathrm{ij}}$ are independent of each other.

\section{Sensitivity analyses}

To confirm the longitudinal results, we performed two sensitivity analyses: (1) The first sensitivity analysis was conducted using the data in which metabolic syndrome parameters and IOP could be measured one or more times in a single fiscal year. As a result, participants had 3-20 visits between April 1999 and March 2009. (2) The second sensitivity analysis was conducted using the data for which the age of participants was restricted to 1944 years. This was done because the data suggested that participants aged less than 45 years were more likely to be lost to follow-up, and the main longitudinal results were deduced primarily from middle-aged participants.

All statistical analyses were performed using SAS statistical software (V.9.3, SAS Institute, Cary, North Carolina, USA) Descriptive statistics were reported as means and SDs; the point estimates were reported with $95 \%$ CIs. All reported $p$ values were two-sided, and $p<0.05$ was considered statistically significant.

\section{RESULTS}

\section{Cross-sectional study}

Table 1 shows the characteristics of the 10122 men and 9885 women who were included in the cross-sectional analyses and underwent medical check-ups between April 2008 and March 2009. The mean (SD) values for men were as follows: age, 54.3 (11.6) years; IOP, 12.9 (2.9) mmg; BMI, 23.4 (2.9) kg/m²; waist circumference, 84.8 (7.9) cm; HDL-C levels, 1.39 (0.35) $\mathrm{mmol} / \mathrm{L}$ or $53.9 \quad(13.4) \mathrm{mg} / \mathrm{dL}$; triglyceride levels, 1.46 (1.02) $\mathrm{mmol} / \mathrm{L}$ or $129.1 \quad(90.4) \mathrm{mg} / \mathrm{dL} ; \mathrm{SBP}, 121.3$ (16.3) mm Hg; DBP, 77.1 (10.8) mm Hg; and FPG levels, 5.78 (1.07) $\mathrm{mmol} / \mathrm{L}$ or $104.1(19.3) \mathrm{mg} / \mathrm{dL}$. The mean (SD) values for women were as follows: age, 54.8 (11.1) years; IOP, 12.5 (2.8) mm Hg; BMI, $22.0(3.2) \mathrm{kg} / \mathrm{m}^{2}$; waist circumference, 79.4 (8.8) cm; HDL-C levels, 1.65 (0.36) $\mathrm{mmol} / \mathrm{L}$ or $63.9(14.0) \mathrm{mg} / \mathrm{dL}$; triglyceride levels, 1.00 (0.56) mmol/L or 88.7 (49.9) mg/dL; SBP, 115.0 (17.2) mm Hg; DBP, 70.8 (10.7) mm Hg; and FPG levels, 5.37 (0.74) $\mathrm{mmol} / \mathrm{L}$ or $96.6(13.3) \mathrm{mg} / \mathrm{dL}$. Table 2 represents Pearson's correlation coefficients for IOP in both
Table 1 Characteristics of participants who underwent a medical check-up between April 2008 and March 2009

\begin{tabular}{lcc}
\hline Variables, mean (SD) & $\begin{array}{l}\text { Men } \\
(\mathbf{n}=10122)\end{array}$ & $\begin{array}{l}\text { Women } \\
(\mathbf{n}=9885)\end{array}$ \\
\hline Age, years & $54.3(11.6)$ & $54.8(11.1)$ \\
Intraocular pressure, $\mathrm{mm} \mathrm{Hg}$ & $12.9(2.9)$ & $12.5(2.8)$ \\
Body mass index, $\mathrm{kg} / \mathrm{m}^{2}$ & $23.4(2.9)$ & $22.0(3.2)$ \\
Waist circumference, $\mathrm{cm}$ & $84.8(7.9)$ & $79.4(8.8)$ \\
$\mathrm{HDL}-\mathrm{C}, \mathrm{mmol} / \mathrm{L}$ & $1.39(0.35)$ & $1.65(0.36)$ \\
(HDL-C, $\mathrm{mg} / \mathrm{dL})$ & $53.9(13.4)$ & $63.9(14.0)$ \\
Triglyceride, $\mathrm{mmol} / \mathrm{L}$ & $1.46(1.02)$ & $1.00(0.56)$ \\
(Triglyceride, mg/dL) & $129.1(90.4)$ & $88.7(49.9)$ \\
Systolic blood pressure, & $121.3(16.3)$ & $115.0(17.2)$ \\
mm Hg & & \\
Diastolic blood pressure, & $77.1(10.8)$ & $70.8(10.7)$ \\
mm Hg & & \\
Fasting plasma glucose, & $5.78(1.07)$ & $5.37(0.74)$ \\
mmol/L & & \\
(Fasting plasma glucose, & $104.1(19.3)$ & $96.6(13.3)$ \\
mg/dL) & & \\
\hline HDL-C, high-density lipoprotein cholesterol. &
\end{tabular}

sexes in relation to age and metabolic syndrome parameters. In men, IOP was negatively correlated with age levels and positively correlated with waist circumference, HDL-C levels, triglyceride levels, SBP, DBP and FPG levels. In women, IOP was positively correlated with waist circumference, triglyceride levels, SBP, DBP and FPG levels. Table 3 shows the means and SDs of the IOP levels stratified by the numbers of positive metabolic syndrome parameters. The analysed population in the cross-sectional study was restricted to 15256 participants for whom data for all metabolic parameters, history and medication were available. Individuals with $0,1,2,3,4$ and 5 positive metabolic syndrome parameters showed mean (SD) IOP of 12.2 (2.7), 12.6 (2.8), 12.9 (2.9), 13.3 (2.9), 13.3 (2.8) and 13.5 (2.8) $\mathrm{mm} \mathrm{Hg}$, respectively. The Jonckheere-Terpstra trend test detected statistical significance with $\mathrm{p}<0.0001$ between the number of positive metabolic syndrome parameters and mean IOPs.

\section{Longitudinal study}

The longitudinal study included the data of changes in measured parameters in 15747 participants. The mean (SD) number of visits during the 10-year period among the participants of the longitudinal analyses was 4.34 (2.53) for men and 4.03 (2.42) for women. The mean (SD) follow-up duration was 1711 (929) days for men and 1705 (881) days for women. Table 4 shows the estimated coefficients, 95\% CIs and $\mathrm{p}$ values in the mixed-effects models, analysing the relationship between the change in IOP and the changes in the metabolic syndrome parameters. After adjusting for multiple cardiovascular risk factors, the change in IOP showed negative associations with male sex and ageing and positive associations with increases in HDL-C levels, triglyceride levels, SBP, DBP and FPG levels. 
Table 2 Pearson's correlation coefficients of IOP with age and metabolic syndrome parameters in funduscopically healthy adults

\begin{tabular}{|c|c|c|c|c|}
\hline \multirow[b]{2}{*}{ Parameters } & \multicolumn{4}{|c|}{ Pearson's correlation coefficient with IOP (95\% CI) } \\
\hline & Men $(n=10122)$ & p Value* & Women $(n=9885)$ & p Value ${ }^{\star}$ \\
\hline Age & $-0.10(-0.12$ to -0.08$)$ & $<0.001$ & $-0.003(-0.02$ to 0.02$)$ & 1.00 \\
\hline Waist circumference & $+0.09(0.08$ to 0.11$)$ & $<0.001$ & $+0.09(0.07$ to 0.11$)$ & $<0.001$ \\
\hline HDL-C & $+0.03(0.006$ to 0.05$)$ & $<0.01$ & $+0.0002(-0.02$ to 0.02$)$ & 1.00 \\
\hline Triglyceride & $+0.08(0.06$ to 0.10$)$ & $<0.001$ & $+0.07(0.05$ to 0.09$)$ & $<0.001$ \\
\hline Systolic blood pressure & $+0.17(0.16$ to 0.19$)$ & $<0.001$ & $+0.22(0.20$ to 0.24$)$ & $<0.001$ \\
\hline Diastolic blood pressure & $+0.17(0.15$ to 0.19$)$ & $<0.001$ & $+0.19(0.17$ to 0.21$)$ & $<0.001$ \\
\hline Fasting plasma glucose & $+0.12(0.10$ to 0.14$)$ & $<0.001$ & $+0.15(0.14$ to 0.17$)$ & $<0.001$ \\
\hline
\end{tabular}

\section{Sensitivity analyses}

Table 5 shows the results of the two sensitivity analyses: (1) which allowed multiple measurements in a single fiscal year among the same 15747 participants and (2) in which participant ages were restricted to 19-44 years $(n=5261)$. In the first sensitivity analysis, the estimated coefficients for the longitudinal association between changes in metabolic syndrome parameters and IOP were almost similar to those of the original multivariate analysis. The second sensitivity analysis also suggested little differences in the estimated coefficients between the data of the younger adults and those of the total study participants.

\section{DISCUSSION}

\section{Main findings}

The cross-sectional study indicated that an increase in age was a protective factor against elevated IOP, and

Table 3 Intraocular pressure (IOP) in relation to the numbers of positive metabolic syndrome parameters ${ }^{*}$

\begin{tabular}{|c|c|c|c|}
\hline $\begin{array}{l}\text { Number of } \\
\text { positive } \\
\text { metabolic } \\
\text { syndrome } \\
\text { parameters* }\end{array}$ & $\begin{array}{l}\text { Number of } \\
\text { participants }\end{array}$ & $\begin{array}{l}\text { IOP, } \\
\text { mm Hg, } \\
\text { mean (SD) }\end{array}$ & $\begin{array}{l}\text { p Value } \\
\text { for linear } \\
\text { trend }\end{array}$ \\
\hline 0 & 6171 & $12.2(2.7)$ & $<0.0001$ \\
\hline 1 & 4507 & $12.6(2.8)$ & \\
\hline 2 & 2908 & $12.9(2.9)$ & \\
\hline 3 & 1240 & $13.3(2.9)$ & \\
\hline 4 & 363 & $13.3(2.8)$ & \\
\hline 5 & 67 & $13.5(2.8)$ & \\
\hline \multicolumn{4}{|c|}{$\begin{array}{l}\text { *Five parameters were used for diagnosing a patient with } \\
\text { metabolic syndrome: waist circumference of } \geq 85 \mathrm{~cm} \text { in men and } \\
\geq 90 \mathrm{~cm} \text { in women; triglyceride levels of } \geq 1.7 \mathrm{mmol} / \mathrm{L}(150 \mathrm{mg} / \mathrm{dL} \text { ) } \\
\text { or specific treatment for this lipid abnormality; high-density } \\
\text { lipoprotein cholesterol levels of }<1.03 \mathrm{mmol} / \mathrm{L}(40 \mathrm{mg} / \mathrm{dL} \text { ) in men } \\
\text { and }<1.29 \mathrm{mmol} / \mathrm{L}(50 \mathrm{mg} / \mathrm{dL} \text { ) in women or specific treatment for } \\
\text { this lipid abnormality; systolic blood pressure of } \geq 130 \mathrm{~mm} \mathrm{Hg} \text {, } \\
\text { diastolic blood pressure of } \geq 85 \mathrm{~mm} \mathrm{Hg} \text { or treatment of previously } \\
\text { diagnosed hypertension and fasting plasma glucose levels of } \\
>5.6 \mathrm{mmol} / \mathrm{L}(100 \mathrm{mg} / \mathrm{dL} \text { ) or previously diagnosed type } 2 \text { diabetes } \\
\text { in accordance with the definition of the metabolic syndrome in } \\
\text { International Diabetes Federation. }\end{array}$} \\
\hline
\end{tabular}

increases in HDL-C, triglyceride, SBP, DBP and FPG levels were risk factors for elevated IOP. The longitudinal data over 10 years revealed that ageing decreased IOP and that worsening of triglyceride levels, SBP, DBP and FPG levels elevated IOP.

\section{Interpretation of the models}

The cross-sectional and longitudinal analyses provided different interpretations of the association between metabolic syndrome and IOP. The cross-sectional study showed modest-to-moderate relationships at a single time point, independent of the units of metabolic syndrome parameters (table 2). The cross-sectional study also exhibited a dose-response relationship of the severity of metabolic syndrome to elevated IOP (table 3). Crude and confounder-adjusted changes in IOP per unit increase in each metabolic syndrome parameter as longitudinal associations are presented in table 4 . We believe that this observational study answered the study question regarding which metabolic syndrome parameters contribute to changes in IOP as well as the magnitude of such changes.

\section{Results in the context of other studies}

The results of this study agree with those of previous studies that described $\mathrm{SBP}^{7} 36$ as a moderate risk factor for elevated IOP. Concerning ageing, the results have been inconsistent across populations; while results from Western populations have shown that ageing is positively correlated with IOP, ${ }^{36}{ }^{37}$ results from Asian populations have been consistent with ageing as a protective factor against high IOP. ${ }^{18-20} 22232938$ The present longitudinal results from a Japanese population favour this hypothesis about Asians. Ageing may have the potential to exert an ocular hypotensive effect after adjusting for confounders. In terms of glycated haemoglobin levels that reflect the month-to-month plasma glucose levels, ${ }^{39}$ other univariate longitudinal mixed-effects model analyses demonstrated that an increase of $10 \mathrm{mmol} / \mathrm{mol}$ in glycated haemoglobin levels is associated with a $-0.030 \mathrm{~mm} \mathrm{Hg}$ IOP change (95\% CI -0.061 to 0.002 , $\mathrm{p}=0.07)$ and that an increase of $1 \%$ in glycated 
Table 4 Changes in intraocular pressure with ageing and changes in metabolic syndrome parameters: 10 -year longitudinal study $(n=15747)$

\begin{tabular}{|c|c|c|c|c|c|c|}
\hline \multirow[b]{2}{*}{ Explanatory variable } & \multicolumn{3}{|c|}{ Univariate analyses } & \multicolumn{3}{|c|}{ Multivariate analysis } \\
\hline & Coefficient & $95 \% \mathrm{Cl}$ & p Value & Coefficient & $95 \% \mathrm{Cl}$ & p Value \\
\hline Sex, men & -0.35 & -0.39 to -0.32 & $<0.0001$ & -0.12 & -0.16 to -0.08 & $<0.0001$ \\
\hline Ageing, +10 years & -0.73 & -0.77 to -0.69 & $<0.0001$ & -0.59 & -0.64 to -0.54 & $<0.0001$ \\
\hline $\mathrm{HDL}-\mathrm{C},+1 \mathrm{mmol} / \mathrm{L}$ & +0.28 & 0.21 to 0.35 & $<0.0001$ & +0.42 & 0.35 to 0.49 & $<0.0001$ \\
\hline (HDL-C, +10 mg/dL) & +0.073 & 0.055 to 0.090 & $<0.0001$ & +0.11 & 0.09 to 0.13 & $<0.0001$ \\
\hline Triglyceride, $+1 \mathrm{mmol} / \mathrm{L}$ & +0.095 & 0.077 to 0.11 & $<0.0001$ & +0.092 & 0.073 to 0.11 & $<0.0001$ \\
\hline (Triglyceride, $+10 \mathrm{mg} / \mathrm{dL}$ ) & +0.011 & 0.0086 to 0.013 & $<0.0001$ & +0.010 & 0.008 to 0.012 & $<0.0001$ \\
\hline $\mathrm{SBP},+10 \mathrm{~mm} \mathrm{Hg}$ & +0.16 & 0.15 to 0.17 & $<0.0001$ & +0.090 & 0.077 to 0.10 & $<0.0001$ \\
\hline DBP, $+10 \mathrm{~mm} \mathrm{Hg}$ & +0.20 & 0.19 to 0.22 & $<0.0001$ & +0.085 & 0.067 to 0.10 & $<0.0001$ \\
\hline $\mathrm{FPG},+1 \mathrm{mmol} / \mathrm{L}$ & +0.042 & 0.021 to 0.063 & $<0.0001$ & +0.091 & 0.071 to 0.11 & $<0.0001$ \\
\hline$(\mathrm{FPG},+10 \mathrm{mg} / \mathrm{dL})$ & +0.023 & 0.012 to 0.035 & $<0.0001$ & +0.051 & 0.039 to 0.062 & $<0.0001$ \\
\hline
\end{tabular}

haemoglobin levels is associated with a $-0.032 \mathrm{~mm} \mathrm{Hg}$ IOP change $(95 \%$ CI -0.067 to $0.003, \mathrm{p}=0.07)$. Although an observational study indicated diabetes mellitus as a risk factor for primary open-angle glaucoma, ${ }^{12}$ little is known about the association between high plasma glucose levels and IOP. This study, which showed a positive relationship with FPG levels and a negative relationship with glycated haemoglobin levels, did not provide a clear indication of the association between elevated plasma glucose levels and IOP. With respect to the effect of serum lipids on IOP, some previous studies have shown moderate positive correlations between serum triglyceride levels and $\mathrm{IOP}^{30}{ }^{40-42}$ whereas another study found no association between these two factors. ${ }^{43}$ The present results were inconclusive about the association between HDL-C levels and IOP; our results demonstrated a small cross-sectional association and a moderate longitudinal association between HDL-C levels and IOP. Since elevated total cholesterol levels can be partly attributed to elevated HDL-C levels, ${ }^{44}$ and epidemiological studies have not yet revealed an association between IOP and serum lipids, physiological studies to investigate the presence or absence of this association would be necessary.

\section{Possible reasons for these associations}

Studies have suggested possible mechanisms for the association between cardiovascular risk factors and elevated IOP. In particular, hypertension is linked to an elevated IOP in a physiological manner; SBP, rather than DBP, elevates IOP because peaks of SBP that reach the eye can lead to ultrafiltration. ${ }^{45-47}$ On the other hand, although epidemiological studies have reported obesity as a risk factor for increased $\mathrm{IOP}^{48}$ it has not been clearly explained how lifestyle-related factors elevate IOP. Although unproven, one study attributed this phenomenon observed in obese individuals to the fact that obesity produced excess intraorbital fat tissue, increased episcleral venous pressure and blood viscosity. ${ }^{49}$ Another study in a Korean population, using insulin resistance as an index mediating all obesity-related systemic factors, indicated the necessity of further cohort studies that handle respective obesity-related parameters as independent exposure variables. ${ }^{50}$ With respect to the high

Table 5 Multivariate analyses for the associations of changes in intraocular pressure with ageing and changes in metabolic syndrome parameters.

\begin{tabular}{|c|c|c|c|c|c|c|}
\hline \multirow[b]{2}{*}{ Explanatory variable } & \multicolumn{3}{|c|}{ Sensitivity analysis (1), $n=15747$} & \multicolumn{3}{|c|}{ Sensitivity analysis (2), $n=5261$} \\
\hline & Coefficient & $95 \% \mathrm{Cl}$ & p Value & Coefficient & $95 \% \mathrm{Cl}$ & p Value \\
\hline Sex, men & -0.12 & -0.16 to 0.08 & $<0.0001$ & -0.092 & -0.16 to -0.02 & 0.01 \\
\hline Ageing, +10 years & -0.59 & -0.64 to -0.55 & $<0.0001$ & -0.74 & -0.83 to -0.64 & $<0.0001$ \\
\hline HDL-C, $+1 \mathrm{mmol} / \mathrm{L}$ & +0.42 & 0.35 to 0.49 & $<0.0001$ & +0.44 & 0.30 to 0.57 & $<0.0001$ \\
\hline (HDL-C, +10 mg/dL) & +0.11 & 0.09 to 0.13 & $<0.0001$ & +0.11 & 0.08 to 0.15 & $<0.0001$ \\
\hline Triglyceride, $+1 \mathrm{mmol} / \mathrm{L}$ & +0.091 & 0.073 to 0.11 & $<0.0001$ & +0.096 & 0.065 to 0.13 & $<0.0001$ \\
\hline (Triglyceride, $+10 \mathrm{mg} / \mathrm{dL}$ ) & +0.010 & 0.008 to 0.012 & $<0.0001$ & +0.011 & 0.007 to 0.014 & $<0.0001$ \\
\hline $\mathrm{SBP},+10 \mathrm{~mm} \mathrm{Hg}$ & +0.091 & 0.079 to 0.10 & $<0.0001$ & +0.083 & 0.054 to 0.11 & $<0.0001$ \\
\hline $\mathrm{DBP},+10 \mathrm{~mm} \mathrm{Hg}$ & +0.085 & 0.067 to 0.10 & $<0.0001$ & +0.073 & 0.036 to 0.11 & $<0.0001$ \\
\hline $\mathrm{FPG},+1 \mathrm{mmol} / \mathrm{L}$ & +0.091 & 0.070 to 0.11 & $<0.0001$ & +0.15 & 0.10 to 0.20 & $<0.0001$ \\
\hline$(\mathrm{FPG},+10 \mathrm{mg} / \mathrm{dL})$ & +0.050 & 0.039 to 0.062 & $<0.0001$ & +0.085 & 0.058 to 0.11 & $<0.0001$ \\
\hline
\end{tabular}

(1) Residents underwent health check-ups 3-20 times during 10 years. (2) Residents aged 19-44 underwent health check-ups once per year during 10 years.

DBP, diastolic blood pressure; FPG, fasting plasma glucose; HDL-C, high-density lipoprotein cholesterol; SBP, systolic blood pressure. 
prevalence of elevated IOP that has been observed among patients with diabetes, ${ }^{36}{ }^{48}$ diabetes-related autonomic dysfunction, genetic factors and corneal stiffening may partly explain elevated IOP. $^{24}$ The mechanisms of ageing, which is a risk factor for elevated IOP in Westerners but not in Asians, may be explained by the high prevalence of obesity, hypertension and diabetes in aged Westerners. ${ }^{51}{ }^{52}$ It has been speculated that the ocular hypertensive effects of ageing in Westerners may be a result of the ocular hypertensive effects of obesity, hypertension and diabetes that surpass the actual hypotensive effects of ageing. Concerning the moderate positive association between serum triglyceride levels and IOP in this study, there has been no comparable literature. Since statins reportedly decrease the risk of openangle glaucoma ${ }^{53}$ individuals who had been treated with statins and had relatively low IOP in the data may have produced the observed moderate association between IOP elevation and high serum triglycerides. Whereas age ${ }^{16}$ African-Americans, ${ }^{54}{ }^{55}$ family history, ${ }^{56}$ hypertension, ${ }^{9}$ diabetes ${ }^{57}$ and elevated $\mathrm{IOP}^{58}$ are known risk factors for open-angle glaucoma, the previous and present studies have suggested that age is a protective factor in Asians, and hypertension ${ }^{9} 10$ and high plasma glucose $^{3648}$ are risk factors for elevated IOP.

\section{Strengths and limitations}

The following three factors were the strengths of this study. First, we believe that modelling IOP in relation to ageing, serum lipids, blood pressure and plasma glucose together estimated the amount of IOP attributable to lifestyle-related systemic parameters and addressed the underlying confounding problems. As shown in table 3, the increase in the severity of the metabolic syndrome resulted in a linear increase in IOP. We consider that the consistency between the cross-sectional and longitudinal results reflects the internal validities. Second, the number of participants and the follow-up period in this study were sufficient to investigate the study question. We propose that the results of the study could be extrapolated to Japanese populations. Third, the mixed-effects models in table 4 incorporated repeated measurements and could detect the longitudinal change-to-change relationships.

This study has some limitations. The first is that the data included ophthalmologically healthy participants, most of whom were middle-aged or older. Although the results could be applied to ophthalmologically premedicated people, a study about the intervention of lifestyle modifications on IOP among ophthalmological patients is warranted to ensure applicability to all ophthalmological patients. In addition, since the main longitudinal regression results were deduced primarily from middle-aged individuals, the associations may not be directly applied to younger generations. However, the sensitivity analysis (2) confirmed that the associations in younger generations and those in the total population were almost similar. Another limitation is that IOP was measured using non-contact tonometry. It has been reported that IOP measured by this device is not directly comparable to IOP measured by the Goldmann applanation tonometer, the gold standard instrument. Since the difference in measurements between the Goldmann applanation tonometer and non-contact tonometry may increase with ageing, ${ }^{59}$ IOP measurements would have been more accurate if the thicknesses of the corneas had been measured simultaneously and used to adjust the IOP measurements. This means that IOP in the present data may have been negatively biased in middle-aged or older participants. However, we believe that the ability of the mixed-effects model to estimate the change-to-change relationships minimised this systematic bias. Lastly, this study did not include actual lifestyle-related variables, such as diet, physical activities, smoking, other diseases and socioeconomic status. The study suggests that if people improve their metabolic syndrome parameters by modifying their lifestyles, their IOP will decrease; however, a study with lifestyle interventions would be necessary to confirm this suggestion.

\section{CONCLUSION}

The longitudinal studies revealed that deterioration of waist circumference, blood pressure and FPG accompany the elevation of IOP. The results also suggest that an increase in HDL-C levels accompanies an elevation of IOP; therefore, the results should be carefully interpreted, and further physiological investigations regarding serum lipids and IOP are necessary.

\section{Author affiliations}

${ }^{1}$ Department of Health Sciences, University of Yamanashi, Chuo City, Yamanashi, Japan

${ }^{2}$ Department of Ophthalmology, University of Yamanashi, Chuo City, Yamanashi, Japan

${ }^{3}$ Yamanashi Koseiren Health Care Center, Kofu City, Yamanashi, Japan ${ }^{4}$ Department of Pediatrics, University of Yamanashi, Chuo City, Yamanashi, Japan

${ }^{5}$ Center for Birth Cohort Studies, University of Yamanashi, Chuo City, Yamanashi, Japan

Acknowledgements The authors specially thank Dr Naoki Kondo at the School of Integrated Health Sciences at The University of Tokyo and Professor Rafael Perera-Salazar, Professor Susan Mallett, Dr Richard Stevens, Dr Jason Oke, Dr Emily McFadden, Dr Thomas Fanshawe, Dr Joseph Lee and other biostatistics team members at the Nuffield Department of Primary Care Health Sciences at the University of Oxford for their insightful advice, which helped to improve the analysis and discussion of the manuscript.

Contributors KeK and HY conceived and designed the study. HY analysed the data and wrote the draft. YY, MT, KeK, KaK and ZY collected the data. HY, KeK, KaK, MM, KS, MS, RS, SM and ZY interpreted the results. All authors critically reviewed the manuscript for important intellectual content.

Funding This work was supported by the Ministry of Education, Culture, Sports, Science and Technology of Japan as Grant-in-Aid for Scientific Research (C) $15 \mathrm{~K} 08730$ that was awarded to HY and Grant-in-Aid for Challenging Exploratory Research 15K15221 that was awarded to ZY.

Disclaimer The funders had no role in the study design, data collection and analysis, decision to publish or preparation of the manuscript.

Competing interests None declared. 
Ethics approval The research was approved by the Ethics Review Committee of the Graduate School Department of Interdisciplinary Research at the University of Yamanashi (approval number: H22 No.620).

Provenance and peer review Not commissioned; externally peer reviewed.

Data sharing statement No additional data are available.

Open Access This is an Open Access article distributed in accordance with the terms of the Creative Commons Attribution (CC BY 4.0) license, which permits others to distribute, remix, adapt and build upon this work, for commercial use, provided the original work is properly cited. See: http:// creativecommons.org/licenses/by/4.0/

\section{REFERENCES}

1. Leibowitz HM, Krueger D, Maunder L, et al. The Framingham Eye Study monograph: an ophthalmological and epidemiological study of cataract, glaucoma, diabetic retinopathy, macular degeneration, and visual acuity in a general population of 2631 adults, 1973-1975. Surv Ophthalmol 1979;24:335-610.

2. Sommer A, Tielsch JM, Katz J, et al. Relationship between intraocular-pressure and primary open angle glaucoma among white and black-Americans. The Baltimore Eye Survey. Arch Ophthalmol 1991:109:1090-5.

3. [No authors listed]. The AGIS Investigators. The Advanced Glaucoma Intervention Study (AGIS): 7. The relationship between control of intraocular pressure and visual field deterioration. Am J Ophthalmol 2000;130:429-40.

4. Heijl A, Leske MC, Bengtsson B, et al., Early Manifest Glaucoma Trial Group. Reduction of intraocular pressure and glaucoma progression: results from the Early Manifest Glaucoma Trial. Arch Ophthalmol 2002;120:1268-79.

5. [No authors listed]. Comparison of glaucomatous progression between untreated patients with normal-tension glaucoma and patients with therapeutically reduced intraocular pressures. Collaborative Normal-Tension Glaucoma Study Group. Am J Ophthalmol 1998;126:487-97.

6. [No authors listed]. The effectiveness of intraocular pressure reduction in the treatment of normal-tension glaucoma. Collaborative Normal-Tension Glaucoma Study Group. Am J Ophthalmol 1998;126:498-504

7. Wang S, Xu L, Jonas JB, et al. Major eye diseases and risk factors associated with systemic hypertension in an adult Chinese population: the Beijing Eye Study. Ophthalmology 2009;116:2373-80.

8. Dielemans I, Vingerling JR, Algra D, et al. Primary open-angle glaucoma, intraocular pressure, and systemic blood pressure in the general elderly population. The Rotterdam Study. Ophthalmology 1995;102:54-60.

9. Zhao D, Cho J, Kim MH, et al. The association of blood pressure and primary open-angle glaucoma: a meta-analysis. $A m \mathrm{~J}$ Ophthalmol 2014;158:615-27.e9.

10. Tielsch JM, Katz J, Sommer A, et al. Hypertension, perfusion pressure, and primary open-angle glaucoma: a population-based assessment. Arch Ophthalmol 1995;113:216-21.

11. Xu L, Wang $\mathrm{H}$, Wang $\mathrm{Y}$, et al. Intraocular pressure correlated with arterial blood pressure: the Beijing Eye Study. Am J Ophthalmol 2007;144:461-2.

12. Pasquale LR, Kang JH, Manson JE, et al. Prospective study of type 2 diabetes mellitus and risk of primary open-angle glaucoma in women. Ophthalmology 2006;113:1081-6.

13. Miglior S, Torri V, Zeyen T, et al., EGPS Group. Intercurrent factors associated with the development of open-angle glaucoma in the European glaucoma prevention study. Am J Ophthalmol 2007:144:266-75, E1.

14. Ellis JD, Evans JM, Ruta DA, et al. Glaucoma incidence in an unselected cohort of diabetic patients: is diabetes mellitus a risk factor for glaucoma? DARTS/MEMO collaboration. Diabetes Audit and Research in Tayside Study. Medicines Monitoring Unit. Br J Ophthalmol 2000;84:1218-24.

15. Mukesh BN, McCarty CA, Rait JL, et al. Five-year incidence of open-angle glaucoma: the visual impairment project. Ophthalmology 2002;109:1047-51.

16. Leske MC, Heijl A, Hyman L, et al. Predictors of long-term progression in the early manifest glaucoma trial. Ophthalmology 2007;114:1965-72.

17. Chauhan BC, Mikelberg FS, Balaszi AG, et al. Canadian Glaucoma Study 2. Risk factors for the progression of open-angle glaucoma. Arch Ophthalmol 2008;126:1030-6.
18. $\mathrm{Xu} \mathrm{L,} \mathrm{Li} \mathrm{J,} \mathrm{Zheng} \mathrm{Y}$, et al. Intraocular pressure in northern China in an urban and rural population: the Beijing Eye Study. Am J Ophthalmol 2005;140:913-15.

19. Kashiwagi K, Shibuya T, Tsukahara S. De novo age-related retinal disease and intraocular-pressure changes during a 10-year period in a Japanese adult population. Jpn J Ophthalmol 2005;49:36-40.

20. Kawase K, Tomidokoro A, Araie M, et al. Ocular and systemic factors related to intraocular pressure in Japanese adults: the Tajimi Study. Br J Ophthalmol 2008;92:1175-9.

21. Nomura $\mathrm{H}$, Shimokata $\mathrm{H}$, Ando $\mathrm{F}$, et al. Age-related changes in intraocular pressure in a large Japanese population: a cross-sectional and longitudinal study. Ophthalmology 1999;106:2016-22.

22. Nakano T, Tatemichi M, Miura $\mathrm{Y}$, et al. Long-term physiologic changes of intraocular pressure: a 10-year longitudinal analysis in young and middle-aged Japanese men. Ophthalmology 2005;112:609-16.

23. Zhou Q, Liang YB, Yin Wong TY, et al. Intraocular pressure and its relationship to ocular and systemic factors in a healthy Chinese rural population: the Handan Eye Study. Ophthalmol Epidemiol 2012;19:278-84.

24. Tan GS, Wong TY, Fong CW, et al, Singapore Malay Eye Study. Diabetes, metabolic abnormalities, and glaucoma. Arch Ophthalmol 2009;127:1354-61.

25. Newman-Casey PA, Talwar N, Nan B, et al. The relationship between components of metabolic syndrome and open-angle glaucoma. Ophthalmology 2011;118:1318-26.

26. Magkos F, Yannakoulia M, Chan JL, et al. Management of the metabolic syndrome and type 2 diabetes through lifestyle modification. Annu Rev Nutr 2009;29:223-56.

27. Weih LM, Mukesh BN, McCarty CA, et al. Association of demographic, familial, medical, and ocular factors with intraocular pressure. Arch Ophthalmol 2001;119:875-80.

28. Yoshida M, Ishikawa M, Kokaze $A$, et al. Association of life-style with intraocular pressure in middle-aged and older Japanese residents. Jpn J Ophthalmol 2003;47:191-8.

29. Oh SW, Lee S, Park C, et al. Elevated intraocular pressure is associated with insulin resistance and metabolic syndrome. Diabetes Metab Res 2005;21:434-40.

30. Imai K, Hamaguchi M, Mori K, et al. Metabolic syndrome as a risk factor for high-ocular tension. Int J Obes 2010;34:1209-17.

31. Alberti KGM, Zimmet $P$, Shaw J, et al. The metabolic syndrome-a new worldwide definition. Lancet 2005;366:1059-62.

32. Page EB. Ordered hypotheses for multiple treatments: a significance test for linear ranks. J Am Stat Assoc 1963:58:216-30.

33. McCulloch CE, Neuhaus JM. Generalized linear mixed models. 2nd edn. New York: John Wiley \& Sons, Inc., 2001.

34. Reed D, McGee D, Yano K, et al. Diet, blood pressure, and multicollinearity. Hypertension 1985;7:405-10.

35. O'Brien RM. A caution regarding rules of thumb for variance inflation factors. Qual Quant 2007;41:673-90.

36. Wu SY, Leske MC. Associations with intraocular pressure in the Barbados Eye Study. Arch Ophthalmol 1997;115:1572-6.

37. Dielemans I, de Jong PT, Stolk R, et al. Primary open-angle glaucoma, intraocular pressure, and diabetes mellitus in the general elderly population. The Rotterdam Study. Ophthalmology 1996;103:1271-5

38. Lee JS, Lee SH, Oum BS, et al. Relationship between intraocular pressure and systemic health parameters in a Korean population. Clin Exp Ophthalmol 2002;30:237-41.

39. Koenig RJ, Peterson CM, Jones RL, et al. Correlation of glucose regulation and hemoglobin Alc in diabetes mellitus. $N$ Engl $\mathrm{J} \mathrm{Med}$ 1976;295:417-20

40. Kitamura K, Yokomichi H, Yamagata Z, et al. Changes in intraocular pressure and associated systemic factors over 10 years in subjects without ocular diseases at baseline. J Glaucoma 2014:23:185-9.

41. Park SS, Lee EH, Jargal G, et al. The distribution of intraocular pressure and its association with metabolic syndrome in a community. J Prev Med Public Health 2010;43:125-30.

42. Chang YC, Lin JW, Wang LC, et al. Association of intraocular pressure with the metabolic syndrome and novel cardiometabolic risk factors. Eye (Lond) 2010;24:1037-43.

43. Stewart WC, Sine C, Sutherland S, et al. Total cholesterol and high-density lipoprotein levels as risk factors for increased intraocular pressure. Am J Ophthalmol 1996;122:575-7.

44. Friedewald WT, Levy RI, Fredrickson DS. Estimation of the concentration of low-density lipoprotein cholesterol in plasma, without use of the preparative ultracentrifuge. Clin Chem 1972;18:499-502

45. Bulpitt CJ, Hodes C, Everitt MG. Intraocular pressure and systemic blood pressure in the elderly. Br J Ophthalmol 1975;59:717-20. 
46. Leske MC, Podgor MJ. Intraocular pressure, cardiovascular risk variables, and visual field defects. Am J Epidemiol 1983;118:280-7.

47. Wu SY, Nemesure B, Hennis A, et al., Barbados Eye Studies Group. Nine-year changes in intraocular pressure: the Barbados Eye Studies. Arch Ophthalmol 2006;124:1631-6.

48. Memarzadeh F, Ying-Lai M, Azen SP, et al. Associations with intraocular pressure in Latinos: the Los Angeles Latino Eye Study. Am J Ophthalmol 2008;146:69-76.

49. Mori $\mathrm{K}$, Ando $\mathrm{F}$, Nomura $\mathrm{H}$, et al. Relationship between intraocular pressure and obesity in Japan. Int J Epidemiol 2000;29:661-6.

50. Cheung N, Wong TY. Obesity and eye diseases. Surv Ophthalmol 2007:52:180-95.

51. Wolf-Maier K, Cooper RS, Banegas JR, et al. Hypertension prevalence and blood pressure levels in 6 European countries, Canada, and the United States. JAMA 2003;289:2363-9.

52. Wild S, Roglic G, Green A, et al. Global prevalence of diabetes estimates for the year 2000 and projections for 2030. Diabetes Care 2004;27:1047-53.

53. De Castro DK, Punjabi OS, Bostrom AG, et al. Effect of statin drugs and aspirin on progression in open-angle glaucoma suspects using confocal scanning laser ophthalmoscopy. Clin Exp Ophthalmol 2007;35:506-13.

54. Friedman DS, Wolfs RC, O'Colmain BJ, Eye Diseases Prevalence Research Group. Prevalence of open-angle glaucoma among adults in the United States. Arch Ophthalmol 2004:122:532.

55. Friedman DS, Wolfs RC, O'Colmain BJ. Error in Table and Text in Prevalence of Open-Angle Glaucoma Among Adults in the United States. Arch Ophthalmol 2011;129:1224.

56. Tielsch JM, Katz J, Sommer A, et al. Family history and risk of primary open angle glaucoma: the Baltimore Eye Survey. Arch Ophthalmol 1994;112:69-73.

57. Zhao D, Cho J, Kim MH, et al. Diabetes, fasting glucose, and the risk of glaucoma: a meta-analysis. Ophthalmology 2015;122:72-8.

58. Ekström C. Risk factors for incident open-angle glaucoma: a population-based 20-year follow-up study. Acta Ophthalmol 2012;90:316-21.

59. Tonnu P, Ho T, Newson T, et al. The influence of central corneal thickness and age on intraocular pressure measured by pneumotonometry, non-contact tonometry, the Tono-Pen $\mathrm{XL}$, and Goldmann applanation tonometry. Br J Ophthalmol 2005;89:851-4. 